\title{
Correlation of giant earthquakes with the lunar phase in seven Indo-Pacific subduction zones and around Mongolia
}

\author{
Yoshiaki Fujii ( $\square$ fujii6299@frontier.hokudai.ac.jp ) \\ Hokkaido University https://orcid.org/0000-0003-0431-4093 \\ Yusuke Tsuboi \\ CTI Engineering Co., Ltd. \\ Jun-ichi Kodama \\ Hokkaido University \\ Daisuke Fukuda \\ Hokkaido University
}

Full paper

Keywords: Giant earthquakes, Lunar phase, Subduction zones

Posted Date: April 1st, 2020

DOI: https://doi.org/10.21203/rs.3.rs-18205/v2

License: (c) (i) This work is licensed under a Creative Commons Attribution 4.0 International License.

Read Full License 
1 Correlation of giant earthquakes with the lunar phase in seven Indo-Pacific

2 subduction zones and around Mongolia

3 Yoshiaki Fujii, Rock Mechanics Laboratory, Hokkaido University, N13W8, Sapporo, 060-

4 8628, JAPAN, fujii6299@ frontier.hokudai.ac.jp

5 Yusuke Tsuboi, Department of Dam, CTI Engineering Co., Ltd., 2-4-12, Daimyo, Chuo-ku,

6 Fukuoka, 810-0041, JAPAN, ys-tsuboi@ctie.co.jp

7 Jun-ichi Kodama, Hokkaido University, N13W8, Sapporo, 060-8628, JAPAN,

8 kodama@eng.hokudai.ac.jp

9 Daisuke Fukuda, Hokkaido University, N13W8, Sapporo, 060-8628, JAPAN, d-

10 fukuda@frontier.hokudai.ac.jp

11 Corresponding author: Yoshiaki Fujii

12 


\section{Abstract}

14 Variation in the approximately semidiurnal tidal force affects earthquake occurrence. This

15 paper statistically demonstrates that giant earthquakes occur at lunar phases specific to

16 particular seismic zones. Careful observation during the lunar cycle, especially when

17 seismicity is occurring, should significantly reduce the damage from giant earthquakes. A case

18 study in which a giant earthquake occurred after seismicity was concentrated within the

19 specific lunar phase is discussed.

\section{$21 \quad$ Keywords}

22 Giant earthquakes, Lunar phase, Subduction zones

\section{INTRODUCTION}

25 Several studies have suggested that the approximately semidiurnal tidal force variation affects

26 earthquake occurrence (e.g., Nakata et al., 2008; Cochran et al., 2012). These studies

27 calculated the stress change due to the tidal force for the fault slip orientation for each

28 earthquake and statistically demonstrated that tidal force variation affects earthquake

29 occurrence. The tidal force variation is greatest around the spring tide when the Sun, Earth, 
and Moon are aligned along a straight line and the tidal forces from the Sun and Moon

31 reinforce each other. Therefore, giant earthquakes are expected to occur around the spring tide. From 1900 to the present, giant earthquakes, whose $M_{\mathrm{W}}$ (the moment magnitude) $\geq 8$,

33 were not random, but they did not always occur around the spring tide; instead, the

34 earthquakes were correlated with different parts of the lunar cycle that were specific to each

35 subduction zone (Fujii \& Ozaki, 2012; Ozaki \& Fujii, 2012). However, the lunar phase

36 calculation in those studies was not very accurate and those studies lacked statistical analyses.

37 Therefore, a more accurate lunar phase calculation and the results of such statistical testing

38 are adopted in this paper, thereby providing updated data on giant earthquakes through

39 November 15, 2016. The differences between the lunar phases in the previous studies and the

40 present study are mostly within $6^{\circ}$. However, some big differences due to mistyping were

41 found and corrected. A case study of the Tohoku 2011 earthquake is also shown.

43 locations. Hough (2018) carried out simple simulations and concluded that the occurrence of

$44 M_{\mathrm{W}} \geq 8$ earthquakes $\sim 1900$ onward had nothing to do with lunar phases. However, her

45 conclusion is inadequate since she analyzed all events at the same time without considering 

spring tide of $160^{\circ}$ and $10^{\circ},-20^{\circ}$ may be used instead of $160^{\circ}$ when necessary. The tidal force

their locations.

\section{GIANT EARTHQUAKES AND LUNAR PHASES}

Data on all earthquakes worldwide with an $M_{\mathrm{W}} \geq 8$ between 1900 and November 15,2016 were obtained from the Search Earthquake Archives of the United States Geological Survey (USGS) website (Table 1); their lunar phases were calculated using by the AA.ARC v5.5 developed by Stephen L. Moshier in 1998 downloaded from his web site titled Astronomy and Numerical Software Source Codes (http://www.moshier.net/). Most of the algorithms employed in AA.ARC are from the Astronomical Almanac published by the U.S. Government Printing Office. The lunar phases for the time of earthquake occurrences were calculated by reducing the ecliptic longitude of the Sun from that of the Moon first. Then the delay from the spring tide (Figure 1), which is identical to the lunar phase if it is less than $180^{\circ}$ (new moon to full moon), while $180^{\circ}$ is subtracted from the lunar phase if it is greater than or equal to $180^{\circ}$ (full moon to new moon). To make a group of earthquakes, such as those with delays from the amplitude is almost the same for the same delay from the spring tide if the lunar phase 
difference is $180^{\circ}$. The specific lunar phases during which giant earthquake occurrences were

63

64

66

67

68

69 duration of $l$ degrees is $2 l / 360$. Then, probability $p^{\prime \prime}$ that $m^{\prime}$ earthquakes within $n^{\prime}$ earthquakes concentrated for each subduction zone were more readily found in the previous studies than by using the lunar phase itself (Fujii et al., 2013).

For giant earthquakes in Peru (Figure 2a), there appears to be a specific lunar phase roughly between $30^{\circ}$ and $50^{\circ}$ (Figure 3a). However, the specific lunar phase should be determined objectively. Therefore, the following statistical test was performed. Assuming a random process for earthquake occurrences (the random null hypothesis), the probability $h$ that an earthquake occurs in a fixed specific lunar phase relative to the spring tide with a occur in a specific lunar phase is

72

$$
p^{\prime \prime}=h^{m^{\prime}}(1-h)^{n^{\prime}-m^{\prime}} \times{ }_{n^{\prime}} C_{m^{\prime}}
$$

73 where $h^{m^{\prime}}$ denotes the probability that all $m^{\prime}$ earthquakes occur in the specific lunar phase, $(1-$

$74 h)^{n^{\prime}-m^{\prime}}$ denotes the probability that all $n^{\prime}-m^{\prime}$ earthquakes do not occur in the specific lunar

75 phase, and ${ }_{n} C_{m^{\prime}}$ is the number of $m^{\prime}$-combinations from $n^{\prime}$ elements

$$
76 \quad{ }_{n} C_{m^{\prime}}=\frac{n^{\prime} !}{m^{\prime} !\left(n^{\prime}-m^{\prime}\right) !}
$$

77 that is required because any $m^{\prime}$-combination can occur. The probability $p^{\prime}$ that $m^{\prime}$ or more of $n^{\prime}$ 
earthquakes occur in a fixed specific lunar phase or phases is

$$
p^{\prime}=\sum_{j=m^{\prime}}^{n^{\prime}}\left\{h^{j}(1-h)^{n^{\prime}-j} \times{ }_{n^{\prime}} C_{j}\right\}
$$

This equation is for the case in which the specific lunar phase is fixed. However, $n=n^{\prime}-1$ and $m=m^{\prime}-1$ should be used instead of $n^{\prime}$ and $m^{\prime}$ because the study arbitrarily assumes a specific lunar phase depending on the lunar phase of earthquakes. Finally, the probability $p$ of

83 the random null hypothesis can be calculated as

$84 \quad p=\sum_{j=m}^{n}\left\{h^{j}(1-h)^{n-j} \times{ }_{n} C_{j}\right\}$.

Usually, a random null hypothesis is statistically rejected when $p<0.05$, which means that the occurrence of giant earthquakes does not follow a random process; i.e., there is a specific lunar phase in which giant earthquake occurrences concentrate. phase is between $-16.24^{\circ}$ and $50.21^{\circ}$, so $n^{\prime}$ and $m^{\prime}$ comprise five events and $p=0.019$. Therefore, the assumed specific lunar phase is statistically significant because $p<0.05$.

91 However, an attempt was made to narrow the specific lunar phase because it would be too wide for practical applications. In this attempt, the left-most (\#31) or right-most (\#56) event was assumed to be outside the specific lunar phase. This time, $m^{\prime}$ is four events, the assumed 
94 specific lunar phase was between $32.33^{\circ}$ and $50.23^{\circ}$ or $-16.24^{\circ}$ and $40.32^{\circ}$, and $p=0.00098$

95 or 0.031 , respectively. Note that the specific lunar phase between $32.33^{\circ}$ and $50.23^{\circ}$ is more

96 significant than before excluding \#31. The same process was repeated setting $m^{\prime}=3$ for the

97 assumed specific lunar phases of between $32.33^{\circ}$ and $40.32^{\circ}$ (excluding \#31 and \#56) or

$9835.04^{\circ}$ and $50.23^{\circ}$ (excluding \#31 and \#75); $p=0.0019$ or 0.0071 , respectively. These were

99 statistically less significant and the specific lunar phase between $32.33^{\circ}\left(L_{\mathrm{S}}\right)$ and $50.23^{\circ}\left(L_{\mathrm{E}}\right)$

100 was determined to be the best for Peruvian earthquakes (the red bar in Figure 3a and Table 3). Assuming the occurrence of the next giant earthquake, namely setting $n^{\prime}=6$ and $m^{\prime}=$

1025 , then $p=0.05$ when the duration of the specific lunar phase is $61.66^{\circ}(\Delta L)$. Therefore,

103 statistically, it can be said that the next giant earthquake will occur between $-11.43^{\circ}\left(L_{\mathrm{E}}-\Delta L\right)$

104 and $93.99^{\circ}\left(L_{S}+\Delta L\right)$ (the blue bar in Figure 3a). However, this range is too wide to be of

105 practical use. Therefore, the prediction of the next giant earthquake for $p=0.01$ (duration,

$10639.97^{\circ}$ ) is also shown as the green bar in Figure 3a. Using the above procedure, no significant specific lunar phase was found for the

108 earthquakes in Chile (Figure 2a). The result for giant earthquakes in Southern Chile only is

109 shown (Figure 3b, Table 3). The events \#48-\#50 were regarded as one earthquake because 
they occurred in 33 hours. The specific lunar phase was determined for Alaska (Figures 2b, 3c,

111 Table 3) with a relatively large $p$-value. Specific lunar phases for the Japan Trench (Figures

112 2c and 3d) and Mongolia (Figures 2d and 3e), which is not a subduction zone, were also

113 determined (Table 3). The events \#2 occurred 14 days after \#1 and they were treated as two

114 events.

115

The events \#91 in Sumatra occurred just two hours after \#90. Regarding the two

116 events as one event, a specific lunar phase for giant earthquakes in Sumatra (Figure 2d) was

117 not determined (Figure 3f) because $p=0.0641$. A specific lunar phase was determined for

118 giant earthquakes in the Kuril Islands (Figures $2 \mathrm{c}$ and $3 \mathrm{~g}$ ). However, no specific lunar phase

119 was determined for Samoa and Tonga (Figures 2e and 3h) because $p=0.250$.

120

Figure 4 summarizes the specific lunar phases. Giant earthquakes occur around the

121 spring tide in Peru, Southern Chile, and Alaska, when the tidal stress is greatest. However,

122 giant earthquakes occur at times other than around the spring tide around Mongolia, in the

123 Japan Trench and the Kuril Islands. The mechanism underlying this phenomenon has not been

124 clarified, although our research group is examining the strain rate (Fujii et al., 2013 and 2015;

125 Wang et al., 2016). 


\section{CONSIDERATION OF THE LOWER LIMIT OF MAGNITUDE}

128 The above analyses were performed only for giant earthquakes $\left(M_{\mathrm{W}} \geq 8\right)$, mainly because it is

129 desirable to predict giant earthquakes that can cause significant damage. However, there were

130 too few earthquakes in the above analyses to achieve good statistical power. Using a slightly

131 smaller lower limit produces better results for earthquakes in Peru.

132 The number of earthquakes is increased by lowering the lower limit of magnitude, as

133 shown in Figure 6. A specific lunar phase can be observed for the case where $M_{\mathrm{W}} \geq 7.5$ and $p$

134 is approximately a fifth the value compared with $M_{\mathrm{W}} \geq 8.0$ (Figures 3a and 6a, Table 2). For

$135 M_{\mathrm{W}} \geq 7.0$, the concentration of earthquakes in a specific lunar phase is vague and no lunar

136 phase range with $p$ of less than 0.05 was not found (Figure 6b). Therefore, the lower limit of

$137 \quad M_{\mathrm{W}}=7.5$ is considered to be the best for Peru earthquakes.

140 Let us examine whether the Tohoku 2011 earthquake could be anticipated using the specific

141 lunar phase concept. For the Japan Trench, the specific lunar phase is $49.23^{\circ}$ to $95.71^{\circ}$ (Table 
142 2). Excluding the Tohoku 2011 earthquake (\#89), i.e., setting $n^{\prime}=6$ and $m^{\prime}=5$, the same

143 specific lunar phase was determined for the right five events, with a slightly greater $p=0.018$

144 (Figure 7). The lunar phases for the next giant earthquake were determined as shown in

145 Figure 7.

On March 9, 2011, an $M_{\mathrm{W}} 7.2$ foreshock occurred during the specific lunar phase for

147 the next giant earthquake with $p=0.01$ (Figure 8 ). A tsunami watch $(\leq 0.5 \mathrm{~m})$ was issued and

148 then lifted (Table 3). Subsequently, another large foreshock $\left(M_{\mathrm{W}} 6.6\right)$ occurred in the specific

149 lunar phase. A tsunami watch was again issued and lifted. However, small foreshocks

150 continued to occur, and the mainshock occurred $31 \mathrm{~h}$ later, within the specific lunar phase for

151 giant earthquakes which could have been determined before the mainshock. The lunar phase

152 for the next giant earthquake with $p=0.05$ is too wide and it would be impractical to have

153 people remain evacuated until it ended. However, if people had known that there was a

154 specific lunar phase for the next giant earthquake with $p=0.01$, and had remained evacuated

155 for another 31 hours, the number of victims would have been greatly reduced. 
158 Statistically, giant earthquakes can occur during the specific lunar phases to some of the

159 subduction zones or around Mongolia. Heightened attention during the dangerous portion of

160 the lunar period in each seismic zone, especially when seismicity is occurring, should reduce

161 the damage from giant earthquakes. An example in which a giant earthquake occurred in the

162 specific lunar phase after seismic activity in the lunar phase for the next giant earthquake, was

163 discussed. It is necessary to clarify the mechanisms underlying why giant earthquakes occur

164 around the neap tides in some seismic zones and to examine additional case studies to show

165 the effectiveness of the specific lunar phase concept.

166

167 DECLARATIONS

168

169 Abbreviations

$170 \quad M_{\mathrm{W}}$ : the moment magnitude

171 USGS: the United States Geological Survey 
174 The datasets generated during and/or analysed during the current study are available from the

175 corresponding author on reasonable request.

176

177 Competing interests

178 The authors declare that they have no conflict of interest.

179

$180 \quad$ Funding

181 This research received no external funding.

182

183 Authors' contributions

184 Conceptualization: YF and YT; data collection and analysis: YT; writing and original draft

185 preparation: YF and JK ; review and editing: JK and DF All authors read and approved the

186 final manuscript.

188 Acknowledgements

189 We used databases at websites belonging to the United States Geological Survey and the 
190 Japan Meteorological Agency. The lunar phase was calculated using AA.ARC by Stephen L.

191 Moshier. The authors express their gratitude.

192

193 REFERENCES CITED

194 Astronomy and Numerical Software Source Codes, http://www.moshier.net/ (accessed on Nov.

$19514,2016)$.

196 Cochran E, Vidale J, Tanaka S (2012) Earth tides can trigger shallow thrust fault earthquakes,

197 Science, 306:1164-1166.

198 Database on Seismic Intensity by JMA (in Japanese),

199 http://www.data.jma.go.jp/svd/eqdb/data/shindo/index.php.

200 Fujii Y, Ozaki Y (2012) Date, lunar phase and time of giant earthquakes might be specified for

201 each subduction zone, Seismological Research Letters, 83:456 (Seismological Society of

202 America 2012 Annual Meeting, Apr. 19, San Diego, US).

203 Fujii Y, Ozaki Y, Fukuda D, Kodama J (2013) Why do giant earthquakes occur at lunar phases

204 specific to each subduction zone? RS2013-1021, 6th Int. Symp. on In-situ Rock Stress, 20-

20522 August 2013, Sendai, Japan. 
Fujii Y, Kodama J, Fukuda D. (2015) Giant earthquakes are occurring at lunar phases specific to each subduction zone, in ISRM Congress 2015 (The 13th. International Congress of

208 Rock Mechanics), Paper 513.

209 Hough SE. (2018) Do Large (Magnitude $\geq 8$ ) Global Earthquakes Occur on Preferred Days of

210 the Calendar Year or Lunar Cycle? Seismic Research Letter, 89(2A):577-581.

211 doi.org/10.1785/0220170154.

212 Nakata R, Suda N, Tsuruoka H (2008) Non-volcanic tremor resulting from the combined

213 effect of earth tides and slow slip events, Nature Geoscience, 1:676-678. doi:

$214 \quad 10.1038 /$ ngeo288.

215 Ozaki Y, Fujii Y (2012) Characteristics of date, time and lunar phase of giant earthquakes for

216 each subduction zone, SSS25-05, Japan Geoscience Union Meeting 2012, May 20,

217 Makuhari, Japan.

218 Search Earthquake Archives by USGS, http://earthquake.usgs.gov/earthquakes/search/

219 Wang Y, Fujii Y, Fukuda D, Kodama J (2016) Kimachi sandstone does not have to fail under

220 larger stress, in EUROCK 2016, Aug. 20, Cappadocia, Turkey. 
Figures

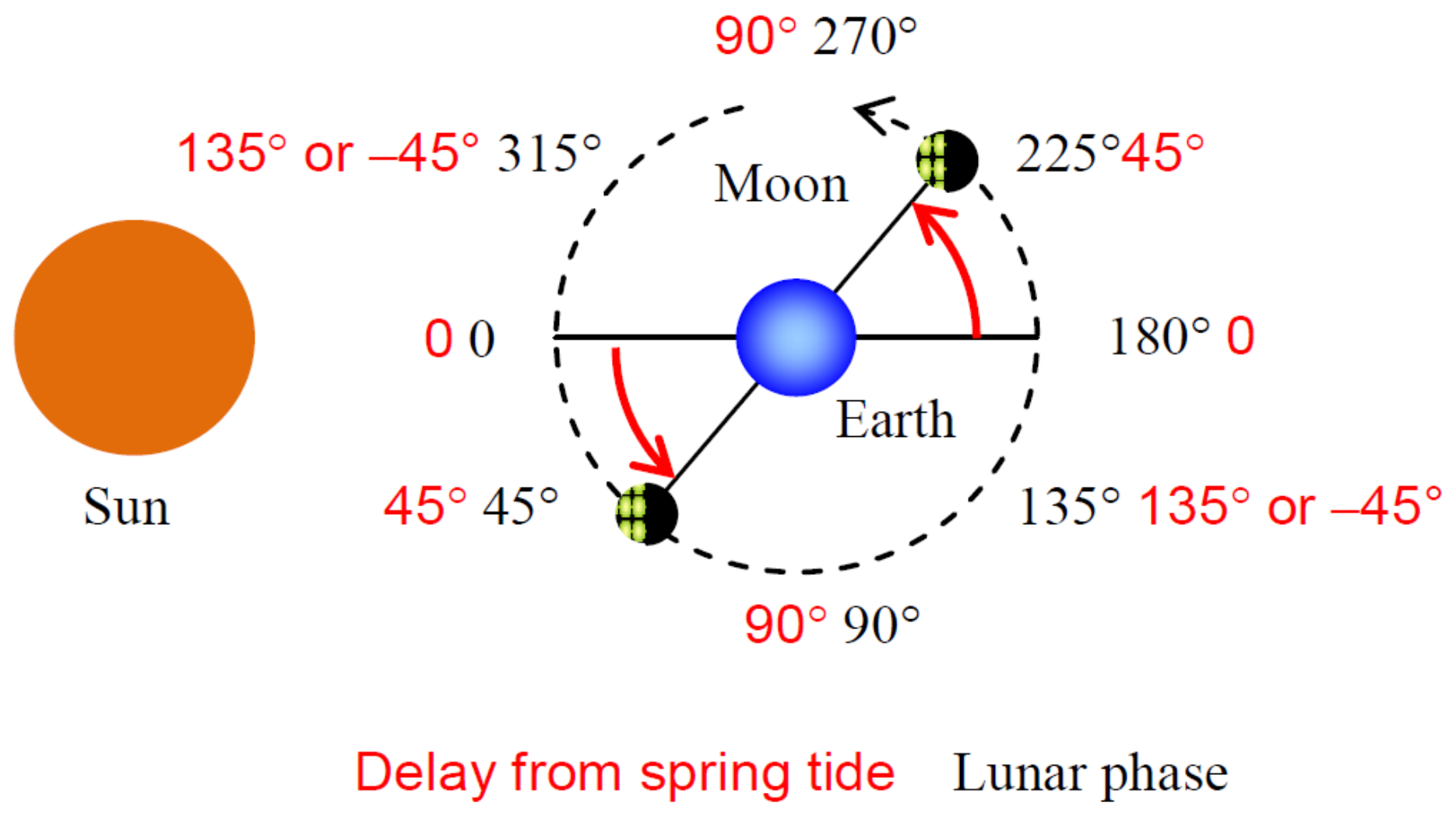

Figure 1

Lunar phase and delay from the spring tide. Not to scale.

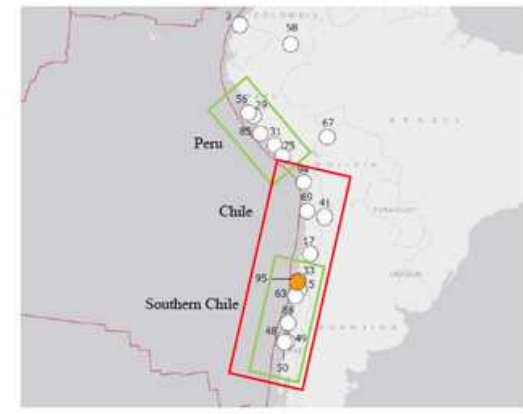

(a) South America

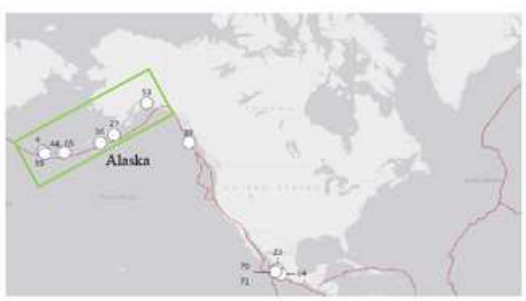

(b) North America

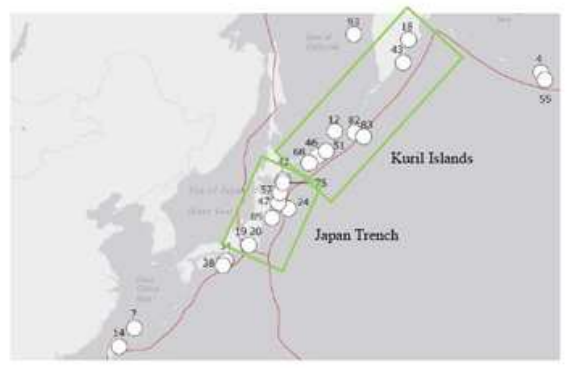

(c) Taiwan to Kamchatka

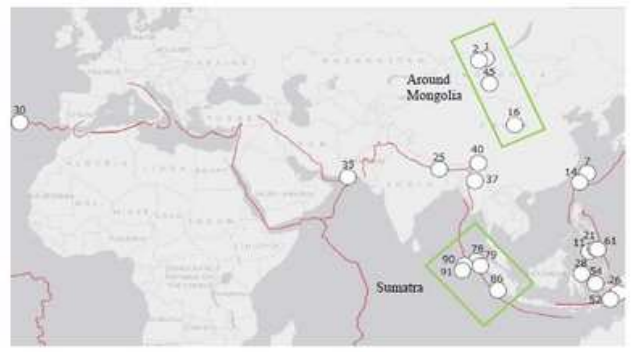

(d) Eurasia and Indonesia

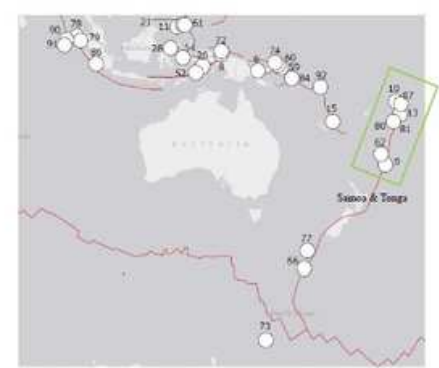

(c) Around Australia 
Figure 2

Giant earthquake distribution between 1900 and November 15, 2016 using the Search Earthquake Archives at the United States Geological Survey (USGS) Website.

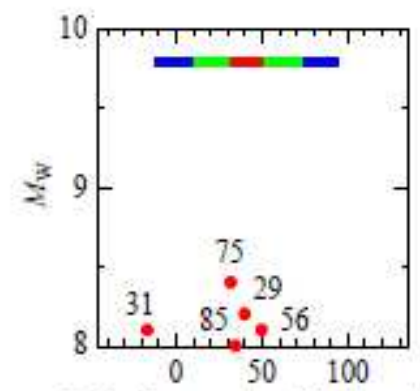

Delay from spring tide (degree)

(a) Peru

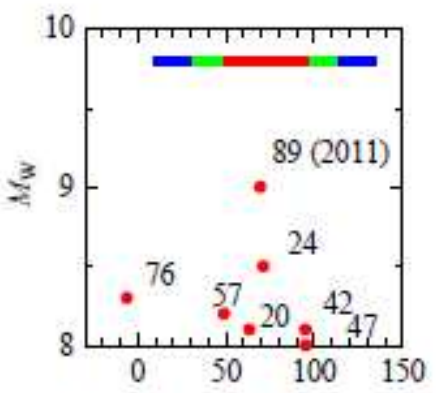

Delay from spring tide (degree)

(d) Japan Trench

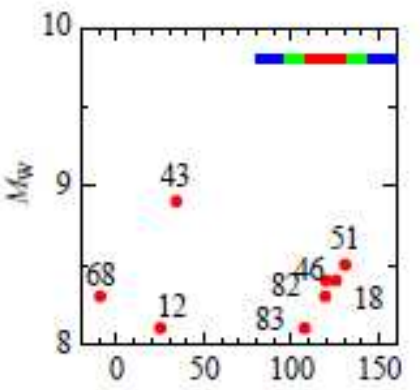

Delay from spring tide (degree)

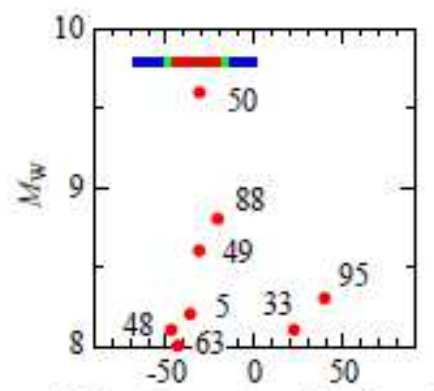

Delay from spring tide (drgree)

(b) Southern Chile

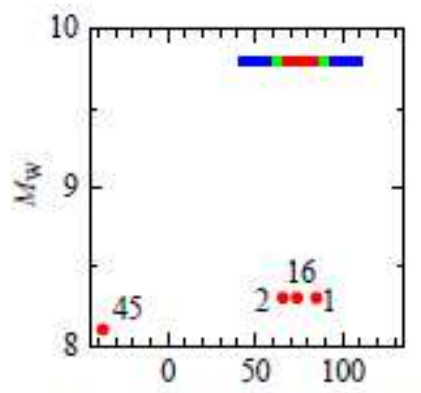

Delay from spring tide (degree)

(e) Around Mongolia

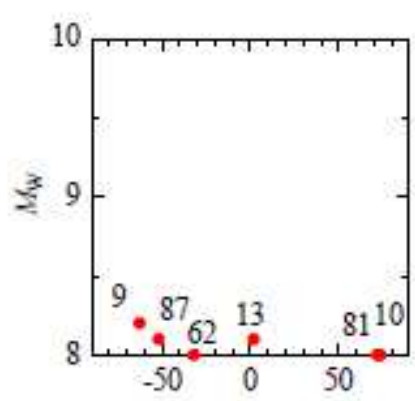

Delay from spring tide (degree)

(h) Samoa and Tonga

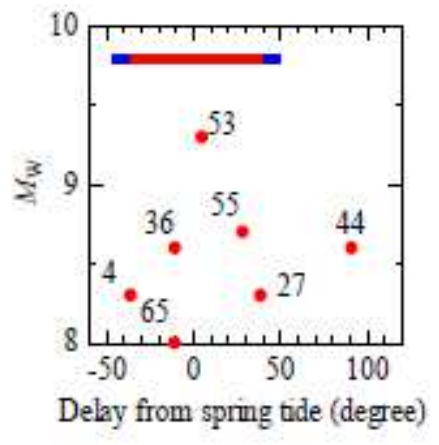

(c) Alaska

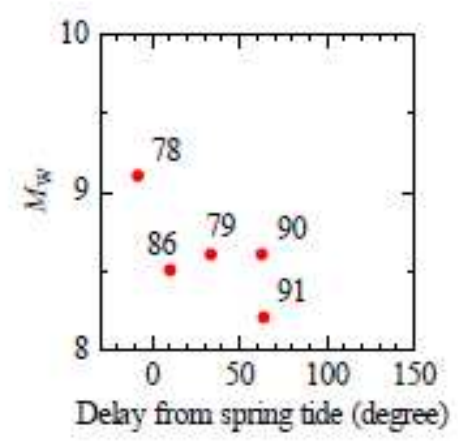

(f) Sumatra

(g) Kuril Islands

Figure 3 
Lunar phase of giant earthquakes delayed from the spring tide. The red, green and blue bars denote the specific lunar phase and the lunar phase for the next giant earthquake with $p=0.01$ and $p=0.05$, respectively.

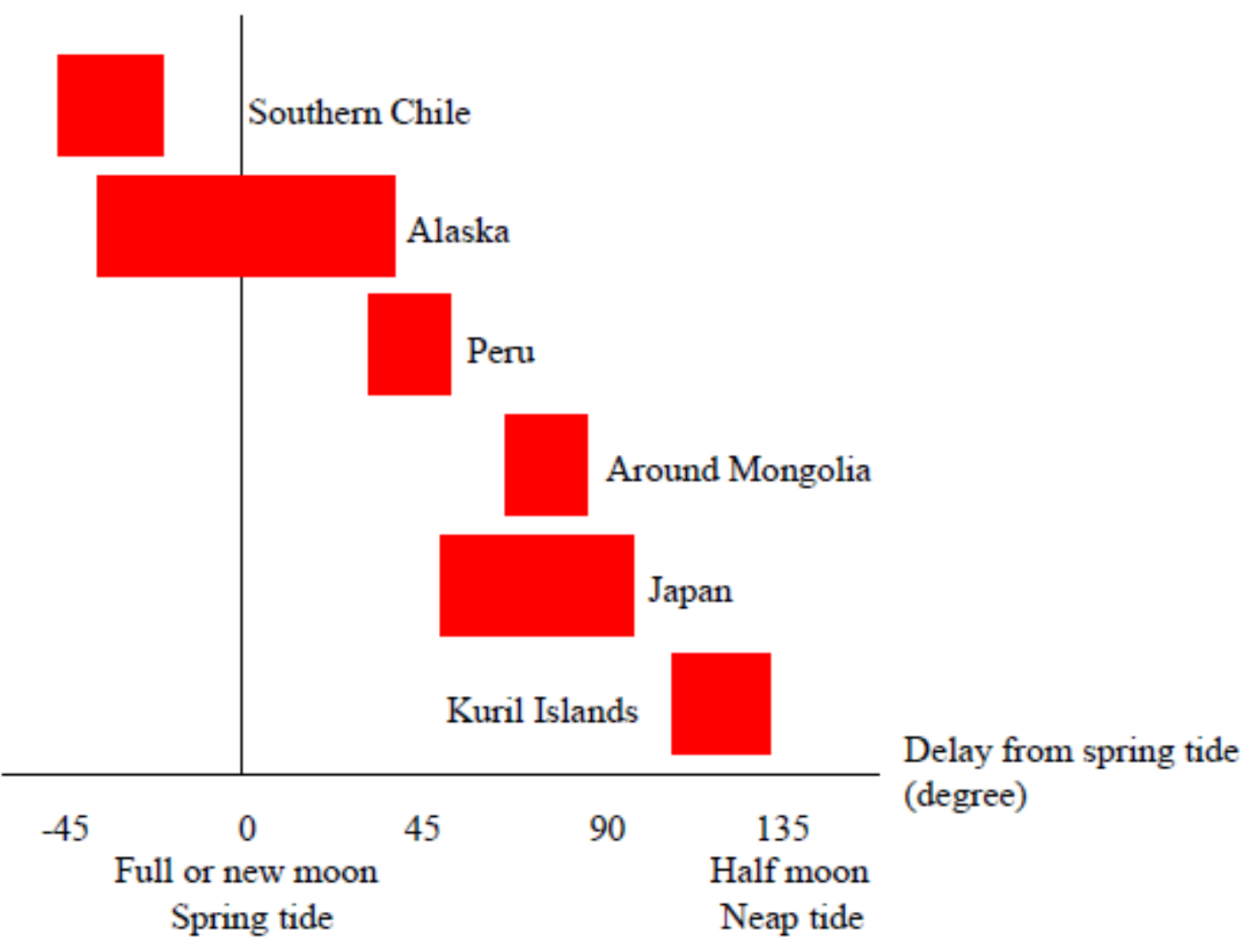

Figure 4

Specific lunar phases in delay from the spring tide for each subduction zone and around Mongolia. 


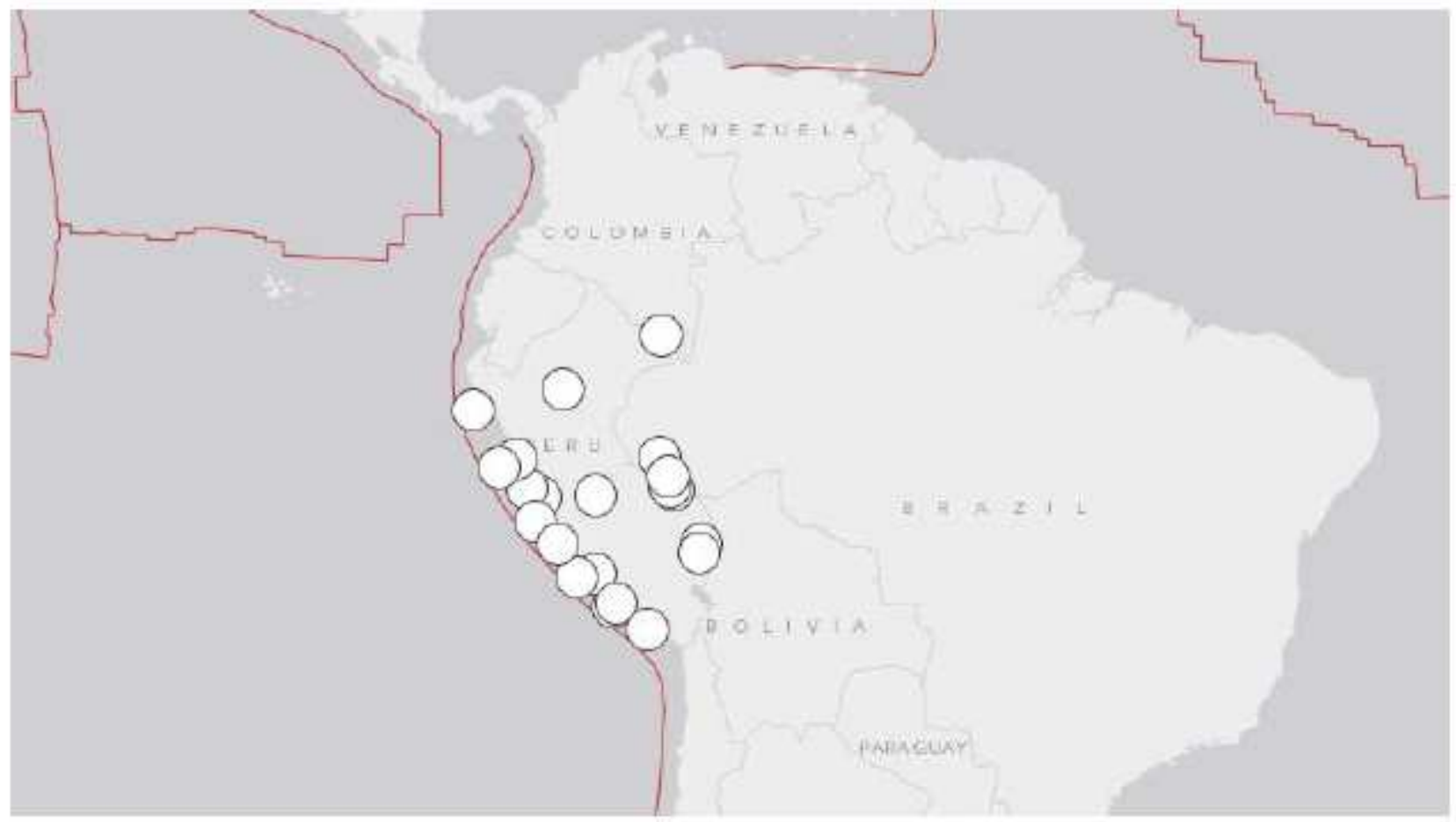

(a) $M_{\mathrm{W}} \geq 7.5$

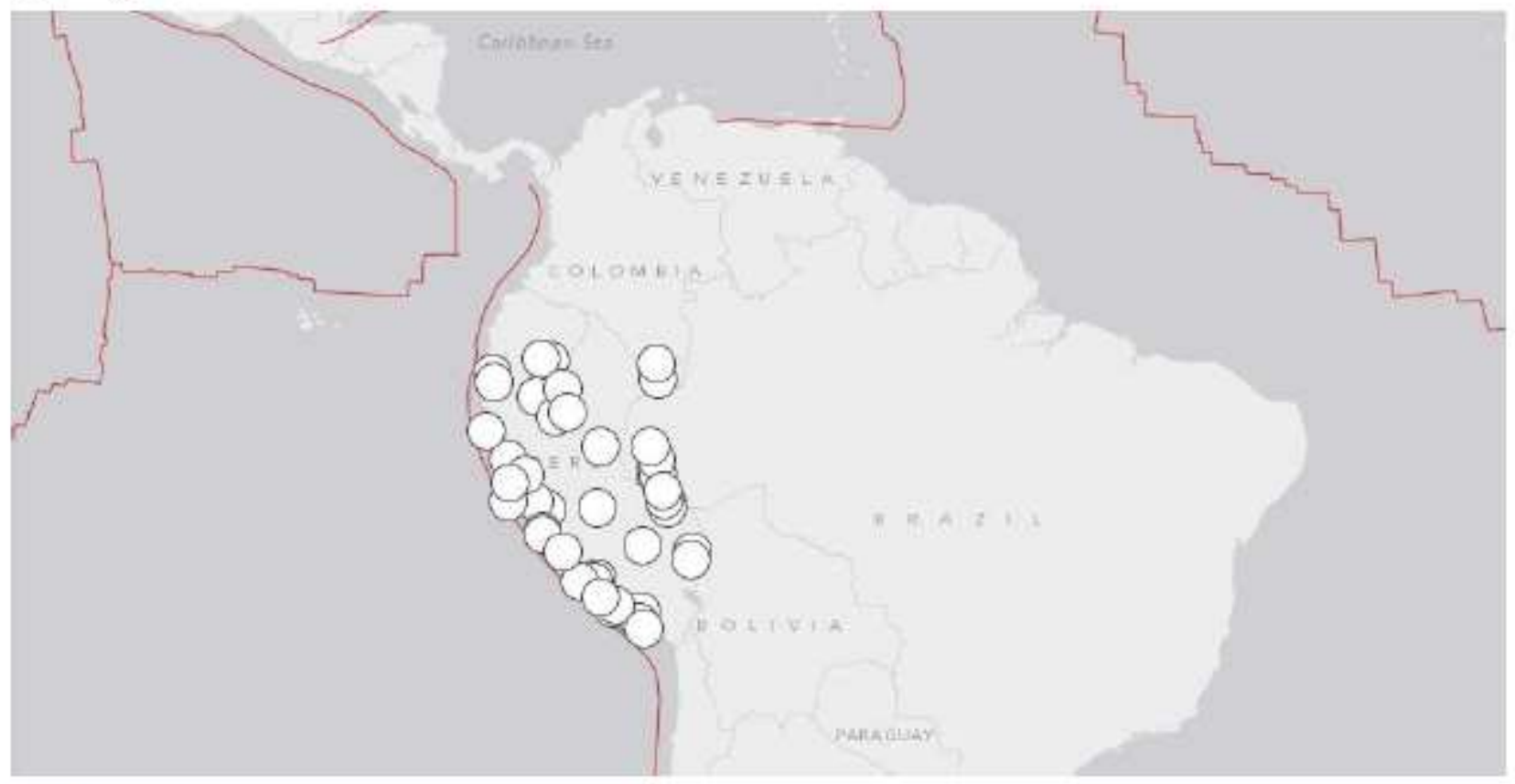

(b) $M_{\mathrm{W}} \geq 7.0$

\section{Figure 5}

Earthquakes in Peru from 1900 to November 15, 2016 using the Search Earthquake Archives at the USGS Website. 


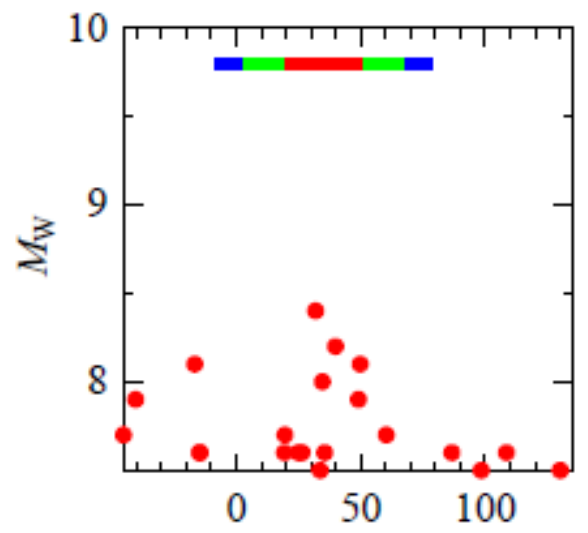

Delay from spring tide (day)

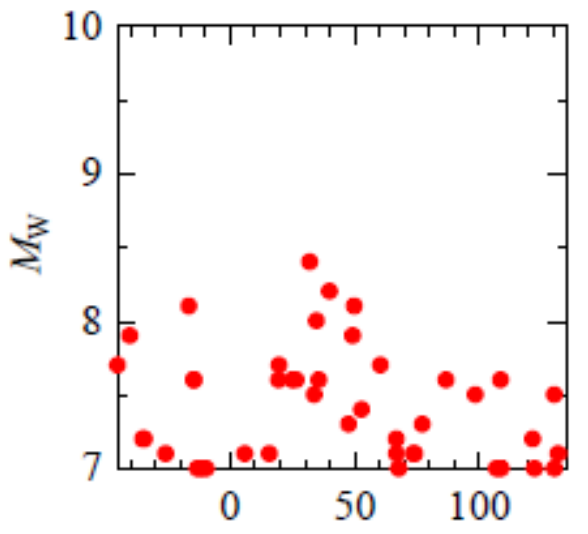

Delay from spring tide (day)
(a) $M_{\mathrm{W}} \geq 7.5(p=0.00067)$
(b) $M_{\mathrm{W}} \geq 7.0$

\section{Figure 6}

The lunar phase of earthquakes in Peru from 1900 to November 15, 2016 (source: the Search Earthquake Archives at the USGS Website).

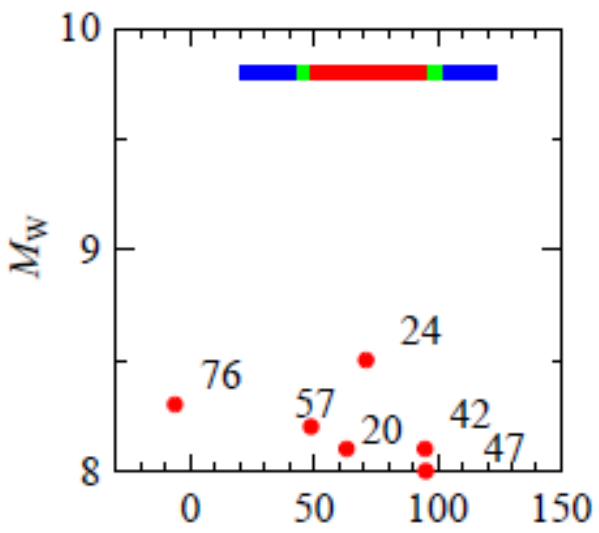

Delay from spring tide (degree)

\section{Figure 7}

The lunar phase of giant earthquakes delayed from the spring tide for earthquakes in the Japan Trench from 1900 to just before the Tohoku 2011 earthquake. The red bar indicates the specific lunar phase before Tohoku $2011(p=0.018)$. The green or blue bar indicates the lunar phase for the next giant earthquake $(p=0.01$ or $p=0.05)$. 


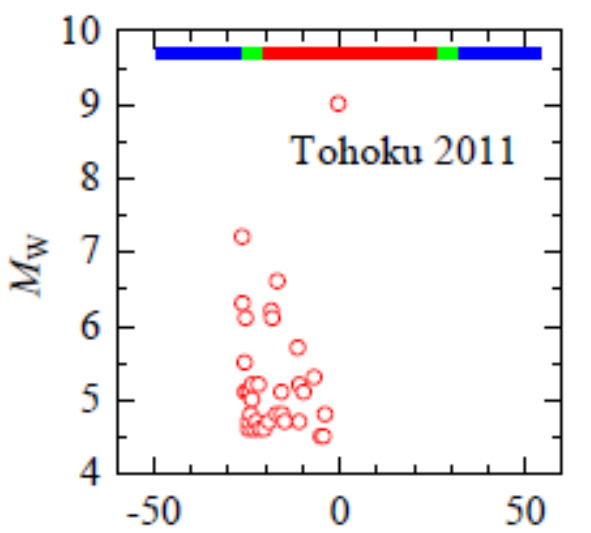

Change in elongation from M9.0 (degree)

\section{Figure 8}

Foreshocks and mainshock of the Tohoku 2011 event (source: Database on Seismic Intensity of the Japan Meteorological Agency (JMA) Website). The red bar denotes the specific lunar phase before Tohoku 2011. The green or blue bar denotes the lunar phase for the next giant earthquake $(p=0.01$ or 0.05).

\section{Supplementary Files}

This is a list of supplementary files associated with this preprint. Click to download.

- FujiiTable2.pdf

- GraphicalAbstract.pdf 